Check for updates

Cite this: Chem. Sci., 2020, 11, 543

¿ All publication charges for this article have been paid for by the Royal Society of Chemistry

Received 31st July 2019

Accepted 20th November 2019

DOI: $10.1039 / \mathrm{c} 9 \mathrm{sc} 03800 \mathrm{k}$

rsc.li/chemical-science

\section{A stable covalent organic framework for photocatalytic carbon dioxide reduction $\uparrow$}

\author{
Zhiwei Fu, (D) a Xiaoyan Wang, (D) a Adrian M. Gardner, ${ }^{\mathrm{b}}$ Xue Wang, ${ }^{\text {ac }}$ \\ Samantha Y. Chong, (D) a Gaia Neri, ${ }^{\mathrm{b}}$ Alexander J. Cowan, (D) ${ }^{\mathrm{b}}$ Lunjie Liu, ${ }^{\mathrm{a}}$ Xiaobo Li, (D) a \\ Anastasia Vogel, (D) ${ }^{a}$ Rob Clowes, ${ }^{a}$ Matthew Bilton, (D) d Linjiang Chen, (D) *ac \\ Reiner Sebastian Sprick (D) *a and Andrew I. Cooper (DD)*ac
}

\begin{abstract}
Photocatalytic conversion of $\mathrm{CO}_{2}$ into fuels is an important challenge for clean energy research and has attracted considerable interest. Here we show that tethering molecular catalysts-a rhenium complex, $\left[\operatorname{Re}(\right.$ bpy $\left.)(\mathrm{CO})_{3} \mathrm{Cl}\right]$-together in the form of a crystalline covalent organic framework (COF) affords a heterogeneous photocatalyst with a strong visible light absorption, a high $\mathrm{CO}_{2}$ binding affinity, and ultimately an improved catalytic performance over its homogeneous Re counterpart. The COF incorporates bipyridine sites, allowing for ligation of the Re complex, into a fully $\pi$-conjugated backbone that is chemically robust and promotes light-harvesting. A maximum rate of $1040 \mu \mathrm{mol} \mathrm{g} \mathrm{g}^{-1}$ for CO production with $81 \%$ selectivity was measured. CO production rates were further increased up to 1400 $\mu \mathrm{mol} \mathrm{g}^{-1} \mathrm{~h}^{-1}$, with an improved selectivity of $86 \%$, when a photosensitizer was added. Addition of platinum resulted in production of syngas, hence, the co-formation of $\mathrm{H}_{2}$ and $\mathrm{CO}$, the chemical composition of which could be adjusted by varying the ratio of COF to platinum. An amorphous analog of the COF showed significantly lower $\mathrm{CO}$ production rates, suggesting that crystallinity of the COF is beneficial to its photocatalytic performance in $\mathrm{CO}_{2}$ reduction.
\end{abstract}

\section{Introduction}

There is now little doubt that the human production of $\mathrm{CO}_{2}$ has contributed to climate change, which will affect life on earth. ${ }^{1}$ One potential approach to reducing $\mathrm{CO}_{2}$ emissions is its conversion into value-added products using solar energy. ${ }^{2,3} \mathrm{~A}$ range of inorganic semiconductors has been investigated as photocatalysts for $\mathrm{CO}_{2}$ reduction, such as $\mathrm{TiO}_{2},{ }^{4} \mathrm{ZrO}_{2},{ }^{5} \mathrm{In}_{2} \mathrm{O}_{3},{ }^{6}$ $\mathrm{CdS},{ }^{7}$ or $\mathrm{ZnGa}_{2} \mathrm{O}_{4} \cdot{ }^{8}$ Unfortunately, many inorganic photocatalysts either have unsuitably aligned conduction/valence band positions or relatively large band gaps, hence limiting visible light absorption. By contrast, the band gap in organic semiconductors can be tuned readily through the incorporation of a diverse range of monomers. ${ }^{9-11}$ In recent years, porous organic materials such as carbon nitrides, ${ }^{\mathbf{1 2}-14}$ conjugated

${ }^{a}$ Department of Chemistry and Materials Innovation Factory, University of Liverpool, 51 Oxford Street, Liverpool L7 3NY, UK. E-mail: ssprick@liverpool.ac.uk; aicooper@ liverpool.ac.uk; lchen@liverpool.ac.uk

${ }^{b}$ Stephenson Institute for Renewable Energy, University of Liverpool, Chadwick Building, Peach Street, Liverpool L69 7ZF, UK

${ }^{c}$ Leverhulme Research Centre for Functional Materials Design, Materials Innovation Factory and Department of Chemistry, University of Liverpool, Oxford Street, Liverpool $L 73 N Y$, UK

${ }^{d}$ Imaging Centre at Liverpool, University of Liverpool, Liverpool L69 3GL, UK $\dagger$ Electronic supplementary information (ESI) available. See DOI: $10.1039 / \mathrm{c} 9 \mathrm{sc} 03800 \mathrm{k}$ microporous polymers (CMPs), ${ }^{15,16}$ covalent triazine-based frameworks (CTFs) ${ }^{17}$ and hyper-crosslinked polymers (HCPs) ${ }^{18}$ have been studied for photocatalytic $\mathrm{CO}_{2}$ reduction. Those organic materials are typically amorphous; by contrast, covalent organic frameworks (COFs) can combine porosity with crystallinity. ${ }^{19-23}$ COFs have been investigated as photocatalysts for water splitting, ${ }^{24,25}$ and for electrocatalytic $\mathrm{CO}_{2}$ reduction. ${ }^{26,27}$ These materials also have potential for direct photocatalytic $\mathrm{CO}_{2}$ reduction: for example, an azine-based $\mathrm{COF}, \mathrm{N}_{3}-\mathrm{COF}$, was shown to exhibit gas phase photocatalytic $\mathrm{CO}_{2}$ reduction. ${ }^{28}$ Likewise, a 2D imine triazine-COF loaded with rhenium ${ }^{29}$ and a $\beta$-ketoenamine-linked COF decorated with both nickel and a light-absorbing dye ${ }^{30}$ were studied for the same reaction. All of these COFs have limited effective conjugation lengths in the $2 \mathrm{D}$ plane of the framework because they are based on imine, azine, or $\beta$-ketoenamine-linkers. This results in blue-shifted absorption on-sets, which limit the ability of the materials to absorb visible light. ${ }^{31,32}$

Here, we used Knoevenagel condensation (Fig. 1a) such that olefins become the COF linkers. ${ }^{31,33,34}$ Our aim was to increase the conjugation length in the framework and hence, perhaps, to improve the performance of these materials for $\mathrm{CO}_{2}$ reduction. The cyanovinyl-groups as a result of the Knoevenagel condensation have been shown to be beneficial for $\mathrm{CO}_{2}$ uptake ${ }^{35}$ which might increase the efficiency of $\mathrm{CO}_{2}$ reduction. The $\mathrm{COF}$ was loaded with $\left[\mathrm{Re}(\mathrm{CO})_{5} \mathrm{Cl}\right]$ giving a heterogeneous analogue of the 
(a)

(b)
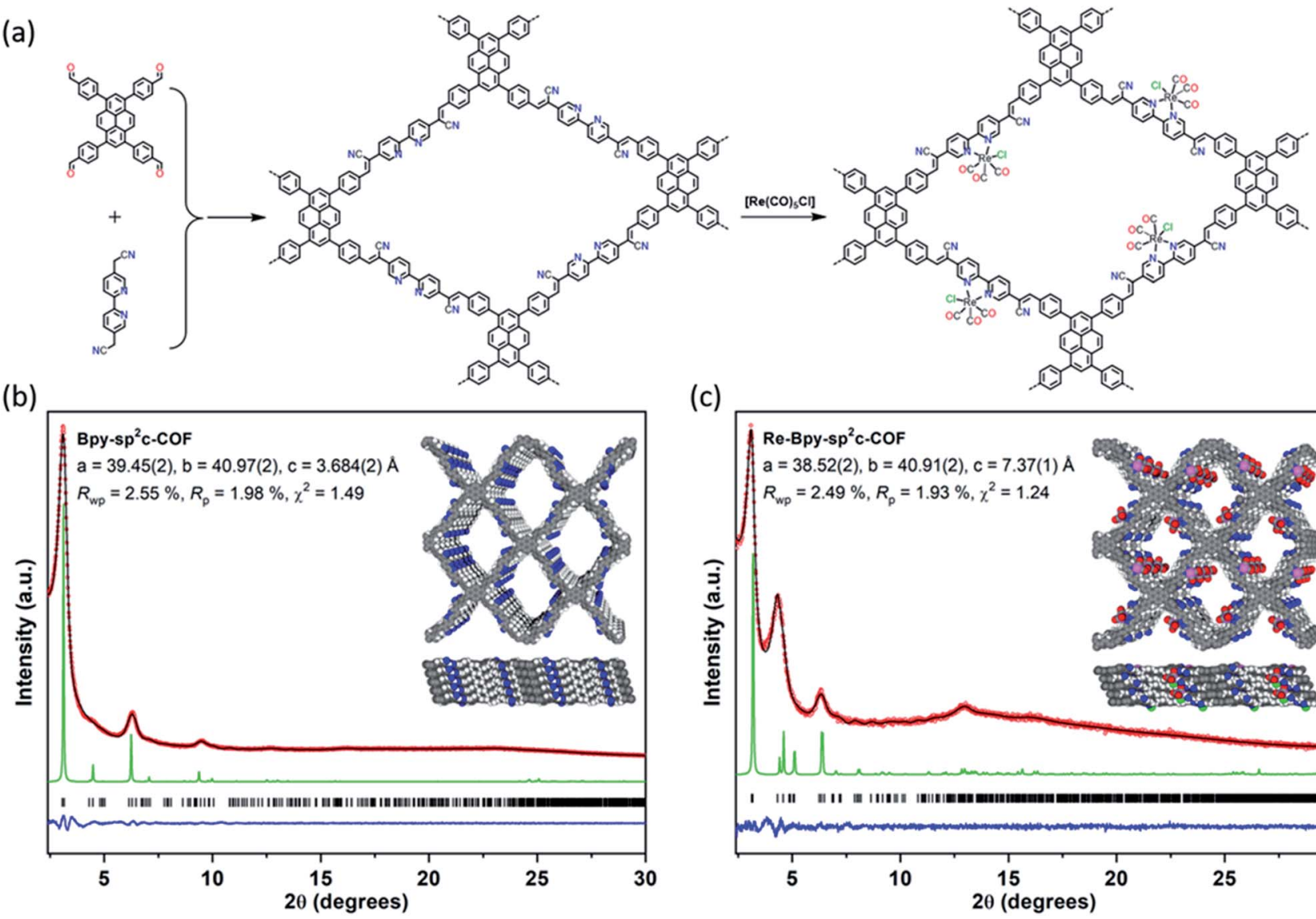

(c)

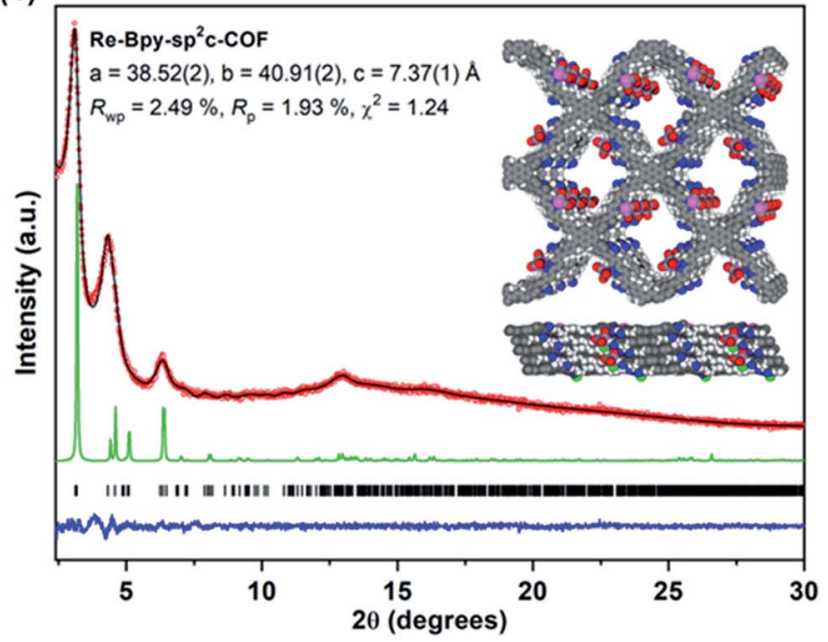

Fig. 1 (a) Synthesis of Bpy-sp ${ }^{2} \mathrm{c}-\mathrm{COF}$ and Re-Bpy-sp ${ }^{2} \mathrm{c}$-COF. Conditions for Bpy-sp ${ }^{2} \mathrm{c}-\mathrm{COF}$ : KOH (4 M) 1,2-dichlorobenzene and 1-butanol (1 : 1 mixture), $120{ }^{\circ} \mathrm{C}, 72$ hours; (b) and (c) PXRD patterns of Bpy-sp ${ }^{2} \mathrm{c}-\mathrm{COF}$ (b) and Re-Bpy-sp ${ }^{2} \mathrm{c}$-COF (c) obtained experimentally (red circles), simulated from the eclipsed AA-stacking mode (green), profiles calculated from Le Bail fitting (black) and residual (blue). Reflection positions are shown by tick marks. Structural models for Bpy-sp ${ }^{2} \mathrm{c}-\mathrm{COF}(\mathrm{b})$ and Re-Bpy-sp ${ }^{2} \mathrm{c}-\mathrm{COF}$ (c) with eclipsed AA stacking patterns, shown parallel to the pore channel along the crystallographic $c$ axis (top) and parallel to the layers (bottom).

well-studied homogeneous catalyst $\left[\operatorname{Re}(\mathrm{bpy})(\mathrm{CO})_{3} \mathrm{Cl}\right]$ with enhanced stability. ${ }^{36}$

\section{Results and discussion}

We synthesized a two-dimensional (2D) $\mathrm{sp}^{2} \mathrm{c}-\mathrm{COF}$ via the Knoevenagel condensation of 1,3,6,8-tetrakis(4-formylphenyl)pyrene (TFPPy) and 5,5'-bis(cyanomethyl)-2,2'-bipyridine in 1,2-dichlorobenzene and 1-butanol at $120{ }^{\circ} \mathrm{C}$ (Fig. 1a). The powder X-ray diffraction (PXRD) pattern of Bpy-sp ${ }^{2}$ c-COF (Fig. $1 \mathrm{~b}$ and S9†) is in good agreement with the profile predicted for the eclipsed (AA) stacked structure (Fig. 1b, inside). Diffraction peaks are observed at $3.1^{\circ}, 4.5^{\circ}, 6.2^{\circ}$, and $9.5^{\circ}$, corresponding to the (110), (200),

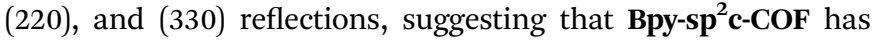
uniform 1D diamond-shaped pores.

Nitrogen sorption experiments were performed at $77 \mathrm{~K}$ and the Brunauer-Emmett-Teller surface area $\left(\mathrm{SA}_{\mathrm{BET}}\right)$ for $\mathbf{B p y}-\mathbf{S p}^{2} \mathbf{c}-$ COF was calculated to be $432 \mathrm{~m}^{2} \mathrm{~g}^{-1}$. This $\mathrm{SA}_{\mathrm{BET}}$ is lower than that predicted for the atomistic model of a perfectly crystalline structure $\left(2041 \mathrm{~m}^{2} \mathrm{~g}^{-1}\right)$, but this is commonly observed for $\mathrm{sp}^{2} \mathrm{c}-$ COFs which typically have surface areas ranging from $322 \mathrm{~m}^{2}$ $\mathrm{g}^{-1}$ for sp ${ }^{2} \mathrm{c}-\mathrm{COF}-2$ (ref. 37) up to $692 \mathrm{~m}^{2} \mathrm{~g}^{-1}$ for sp $\mathrm{sp}^{2}-\mathrm{COF}{ }^{31}$
The pore size distribution profile shows a narrow pore size distribution with a pore width of $2.4 \mathrm{~nm}$ (Fig. 2a, inset curve), further supporting an AA stacking sequence that is predicted to have a pore size of $2.4 \mathrm{~nm}$. Fourier-transform infrared (FT-IR) spectroscopy shows a distinct peak at $2217 \mathrm{~cm}^{-1}$ relating to a $-\mathrm{C} \equiv \mathrm{N}$ vibration band, indicating the formation of $\mathbf{B p y}-\mathbf{s p}^{2} \mathbf{c}-$ COF (Fig. 2c).

Re-complexes for photocatalytic $\mathrm{CO}_{2}$ reduction were first reported in $1983,^{38}$ and they are well studied owing to their high efficiency and selectivity for $\mathrm{CO}$ formation. ${ }^{39,40} \mathrm{Here}$, we used the bipyridine sites in Bpy-sp ${ }^{2} \mathbf{c}-\mathbf{C O F}$ to ligate $\left[\mathrm{Re}(\mathrm{CO})_{5} \mathrm{Cl}\right]$ to give $\mathbf{R e}-$ Bpy-sp ${ }^{2} \mathbf{c}$-COF. The PXRD pattern of the Re-incorporated COF (Fig. $1 \mathrm{c}$ and S10†) shows peaks at $3.1^{\circ}, 4.5^{\circ}, 6.2^{\circ}, 12.9^{\circ}$, corresponding to (110), (200), (220), (-221) reflections predicted for the Re-loaded, AA-stacked model (Fig. 1c).

The BET surface area $\left(\mathrm{SA}_{\mathrm{BET}}\right)$ for Re-Bpy-sp ${ }^{2} \mathbf{c}-\mathbf{C O F}$ was calculated to be $323 \mathrm{~m}^{2} \mathrm{~g}^{-1}$ (Fig. S38†). Scanning transmission electron microscopy (STEM) and energy-dispersive X-ray spectroscopy (EDX) mapping images (Fig. 2b) show a uniform distribution of C, N, O, and Re in Re-Bpy-sp ${ }^{2} \mathbf{c}-\mathbf{C O F}$, further suggesting that the $\operatorname{Re}$ moiety has been incorporated throughout the structure of COFs. Inductively coupled plasma- 
(a)

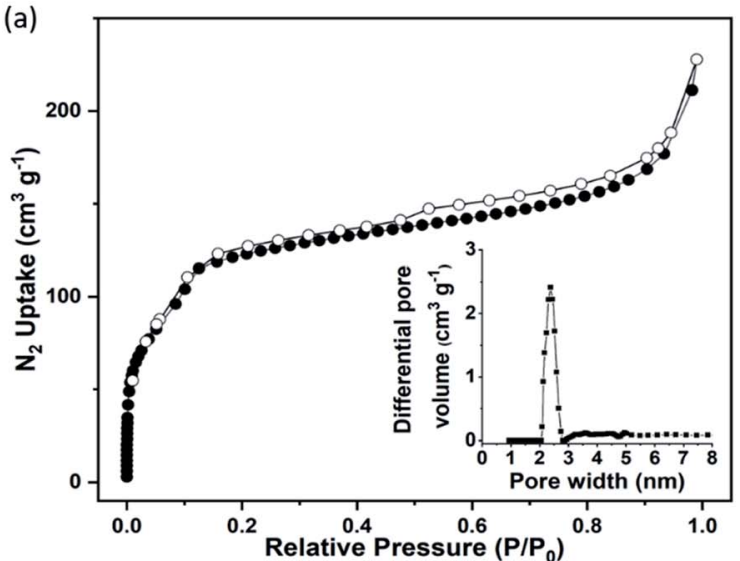

(c)

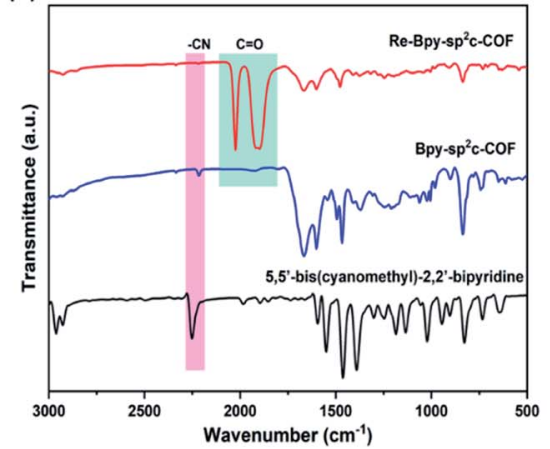

(d) (b)
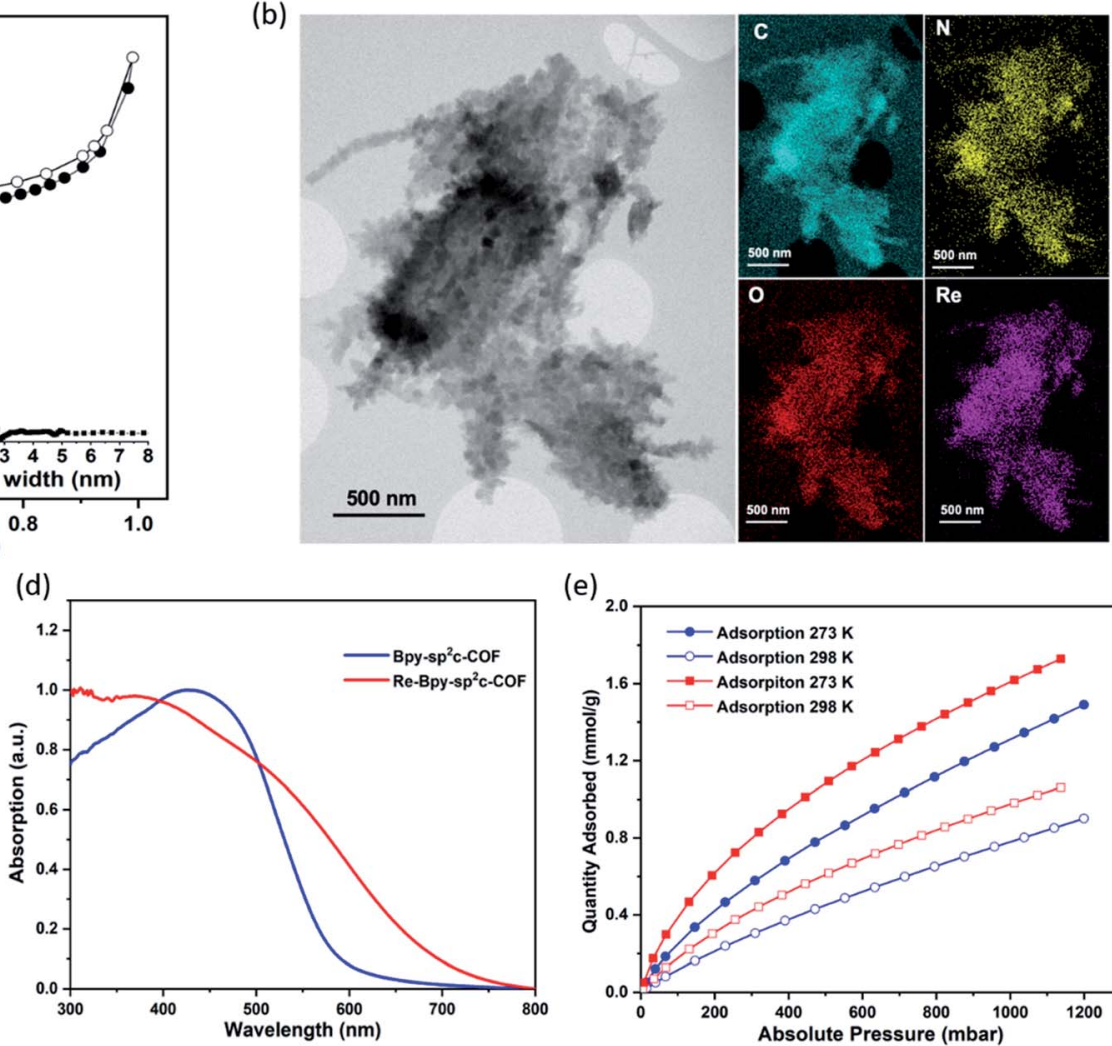

(e)

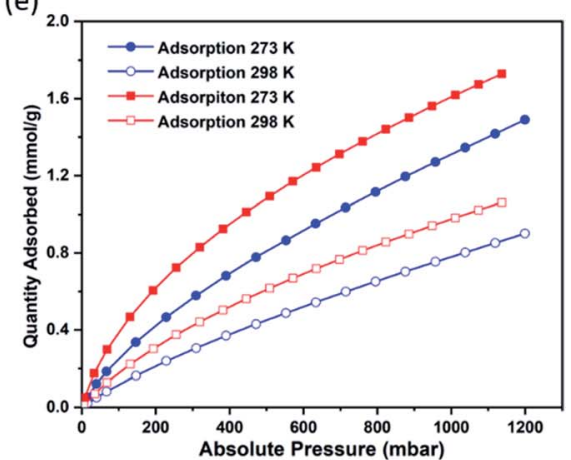

Fig. 2 (a) $\mathrm{N}_{2}$ Adsorption (filled dots) and desorption (open dots) isotherm profiles of Bpy-sp ${ }^{2} \mathrm{c}-\mathrm{COF}$ measured at $77 \mathrm{~K}$. Inset: profile of the

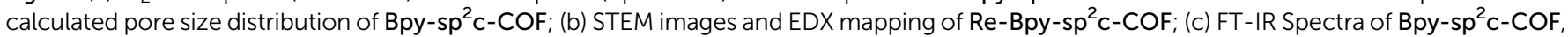

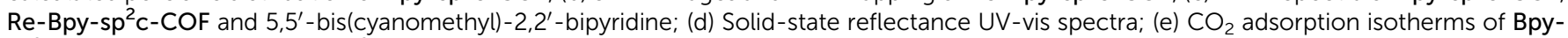
$\mathrm{sp}^{2} \mathrm{c}-\mathrm{COF}$ (blue) and Re-Bpy-sp ${ }^{2} \mathrm{c}-\mathrm{COF}(\mathrm{red})$.

optical emission spectrometry (ICP-OES) measurements show that $18 \mathrm{wt} \%$ of Re has been incorporated into the material. This ratio corresponds to ligation of half of the bipyridine sites by the Re complex, which was also the ratio in the atomistic model built to represent Re-Bpy-sp' ${ }^{2}$-COF (Fig. 1c). The FT-IR spectrum for the Re-modified COF (Fig. 2c) shows new peaks at $1900 \mathrm{~cm}^{-1}, 1917 \mathrm{~cm}^{-1}, 2024 \mathrm{~cm}^{-1}$, corresponding to the COstretching bands of the incorporated $\left[\mathrm{Re}(\mathrm{CO})_{3} \mathrm{Cl}\right]$ complex. ${ }^{29,36}$ UV-visible diffuse reflectance spectra (Fig. 2d) show a red-shift of the absorption edge from $589 \mathrm{~nm}$ to $694 \mathrm{~nm}$ for Re-Bpy$\mathbf{s p}^{2} \mathbf{c}$-COF compared to Bpy-sp $\mathbf{p}^{2} \mathbf{c}-\mathbf{C O F}$. Finally, X-ray photoelectron spectra for Re 4f, $\mathrm{Cl} 2 \mathrm{p}$ and $\mathrm{N} 2 \mathrm{~s}$ regions look very similar for Re-Bpy-sp ${ }^{2} \mathbf{c}$-COF compared to the molecular catalyst $\left[\mathrm{Re}(\mathrm{bpy})(\mathrm{CO})_{3} \mathrm{Cl}\right]$ indicating that complexation of Re is similar in both cases (Fig. S40†).

We next studied the $\mathrm{CO}_{2}$ uptake for this material up to 1200 mbar at both 273 and 298 K. Re-Bpy-sp ${ }^{2}$ c-COF adsorbs $1.7 \mathrm{mmol}$ $\mathrm{g}^{-1} \mathrm{CO}_{2}$ at $273 \mathrm{~K}$ and $1.1 \mathrm{mmol} \mathrm{g}^{-1}$ at $298 \mathrm{~K}$ (Fig. 2e). Re-Bpy$\mathbf{s p}^{2} \mathbf{c}$-COF has a high isosteric heat of adsorption $\left(31 \mathrm{~kJ} \mathrm{~mol}^{-1}\right)$, showing that the $\mathrm{COF}$ has good affinity toward $\mathrm{CO}_{2}$ (Fig. S19†).

Photocatalytic $\mathrm{CO}_{2}$ reduction experiments were conducted in a quartz flask under 1 atmosphere $\mathrm{CO}_{2}$ in a mixture of acetonitrile $(\mathrm{MeCN})$ and triethanolamine (TEOA) in $30: 1$ ratio and under visible light illumination $(\lambda>420 \mathrm{~nm}, 300 \mathrm{~W}$ Xe light source). TEOA acts as the sacrificial electron donor and proton source, while MeCN is used to disperse the catalyst. Over a total of 17.5 hours irradiation under visible light (Fig. S16†), Re-Bpy$\mathbf{s p}^{2} \mathbf{c}$-COF produced CO with a rate of $1040 \mu \mathrm{mol} \mathrm{g}^{-1} \mathrm{~h}^{-1}$ and $81 \%$ selectivity over $\mathrm{H}_{2}$, which equals to a TON of 18.7 for CO, outperforming its homogeneous counterpart under the same conditions, which is deactivated after 3 hours with a TON of 10.3 (Fig. S16†).

An apparent quantum yield (AQY) of $0.5 \%$ was measured at $420 \mathrm{~nm}$ for $\mathrm{CO}$ production. The small amount of $\mathrm{H}_{2}$ possibly originates from competing proton reduction of water traces in the TEOA or oxidative dehydrogenation of TEOA. ${ }^{13}$ In the absence of the Re-complex, Bpy-sp ${ }^{2} \mathbf{c}$-COF only generated trace amounts of $\mathrm{CO}$ while $\mathrm{H}_{2}$ was not detected. No other liquid phase products, i.e. $\mathrm{HCOOH}$ and methanol, were observed.

The combination of $\mathrm{CO}_{2}$ conversion rate and $\mathrm{CO} / \mathrm{H}_{2}$ selectivity of Re-Bpy-sp ${ }^{2} \mathbf{c}-\mathbf{C O F}$ compares favorably with other reported COFs (see Table S3 $\dagger$ ). For example, a rhenium modified 2D imine triazine-COF produced around $750 \mu \mathrm{mol} \mathrm{g}^{-1} \mathrm{~h}^{-1} \mathrm{CO}$ with $98 \%$ selectivity, ${ }^{29}$ and a $\beta$-ketoenamine-linked COF modified with nickel, plus the use of an additional dye, gave a CO production rate of $811 \mu \mathrm{mol} \mathrm{g}^{-1} \mathrm{~h}^{-1} \mathrm{CO}$ with $96 \%$ selectivity. ${ }^{30}$ These comparisons should be made with caution, though, since photocatalytic rates also depend strongly on the precise experimental set-up that is used. ${ }^{41}$ 
Control experiments were carried out to confirm that the source of the CO generated is indeed a photocatalytic process (Table S2 $\dagger$ ). Under an argon atmosphere in absence of $\mathrm{CO}_{2}$, ReBpy-sp $^{2}$ c-COF generated $14.9 \mu \mathrm{mol} \mathrm{g}^{-1} \mathrm{~h}^{-1} \mathrm{CO}$ and $285.3 \mu \mathrm{mol}$ $\mathrm{g}^{-1} \mathrm{~h}^{-1} \mathrm{H}_{2}$. The small amount of $\mathrm{CO}$ produced is possibly a result of decomposition of organic residues during photocatalysis $^{1}$ or decomposition of TEOA as an ineffective sidereaction. ${ }^{13}$ No gas production was observed in the dark or in the absence of hole scavenger. Experiments with isotopically labelled ${ }^{13} \mathrm{CO}_{2}$ resulted in the formation of ${ }^{13} \mathrm{CO}$, strongly suggesting that $\mathrm{CO}_{2}$ was the source of the produced $\mathrm{CO}$ (Fig. 3a).

Re-Bpy-sp ${ }^{2}$ c-COF appears to be stable under the photocatalysis conditions, evident from the post-illumination FT-IR spectra (Fig. S7 $\dagger$ ) of the sample after 17.5 hours of continuous visible light illumination $(\lambda>420 \mathrm{~nm}, 300 \mathrm{~W}$ Xe light source). The material also retains most of its crystallinity and PXRD patterns show that some order is retained after photolysis for 17.5 hours (Fig. S11†). This shows that the material has very good stability compared to other previous reports. ${ }^{29,30}$ When the run was extended to a total of 50 hours a further loss of crystallinity is observed (Fig. S43 and S44 $\dagger$ ) along a loss of activity, highlighting that stability is still one of the important challenges in the field. Nevertheless, it seems that in making a heterogeneous analogue of $\left[\mathrm{Re}(\mathrm{bpy})(\mathrm{CO})_{3} \mathrm{Cl}\right]$ an increase in stability is observed (Fig. S43†), possibly by preventing the formation of the dimer of the Re-complex ${ }^{36}$ which can occur with $\mathrm{Re}(\mathrm{bpy}) \mathrm{CO}_{3} \mathrm{Cl}$ in solution, or by the shielding of the Re- centre within the COF structure from photodecomposition side reactions. ${ }^{42}$

Photoelectrochemical experiments were conducted using FTO glass as a photocathode in $0.1 \mathrm{M} \mathrm{Na}_{2} \mathrm{SO}_{4}$ solution (Fig. 3b). All samples were tested at a constant voltage of $0.5 \mathrm{~V} v s$. reversible hydrogen electrode (RHE). The photocurrent of ReBpy-sp ${ }^{2} \mathbf{c}-\mathbf{C O F}$ photocathode was about $2 \mu \mathrm{A} \mathrm{cm}^{-1}$, which was more than four times higher than a Re-free Bpy-sp ${ }^{2} \mathbf{c}-\mathbf{C O F}$ photoanode. Additionally, Nyquist plots (Fig. 3c) showed the arc

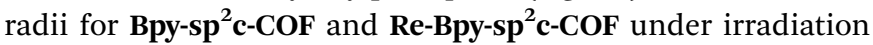
were smaller than those in dark, verifying that charge carriers

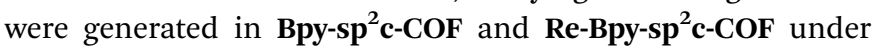
irradiation. The Nyquist plots of Re-Bpy-sp $\mathbf{~}^{2} \mathbf{c}-\mathbf{C O F}$ under irradiation have smaller semicircles than those of Bpy-sp $\mathbf{p}^{2} \mathbf{c}-\mathbf{C O F}$. Both measurements taken together show that the Re bearing material acts as a better photo-electro catalyst indicating that the material is better at separating and transferring charges, which is also in line with computational predictions (vide infra).

We then went on to use emission spectroscopy to study the mechanism of the photocatalysis for the Re loaded Bpy-sp ${ }^{2} \mathbf{c}-$ COF. The photocatalyst Bpy-sp ${ }^{2} \mathbf{c}-\mathbf{C O F}$ in acetonitrile suspension shows the presence of two emissive states, with $\lambda_{\max }$ at 475 and $640 \mathrm{~nm}$. The excitation spectrum shows the $640 \mathrm{~nm}$ emission arises from a broad range of absorption bands in the UV/vis spectrum (from 300 to $500 \mathrm{~nm}$ ), in contrast the sharp emission band centred at $475 \mathrm{~nm}$ is a result of excitation into a single band at $390 \mathrm{~nm}$ (Fig. S20†). Time-correlated single-photon (a)

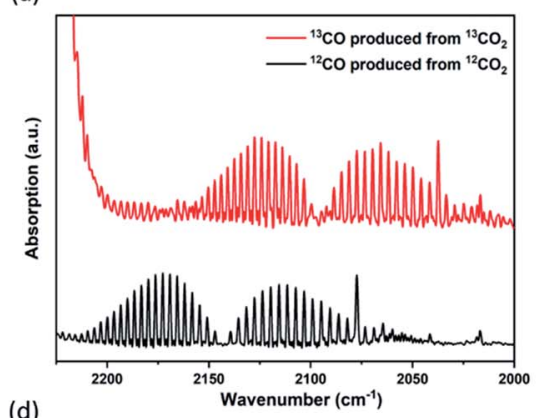

(d)

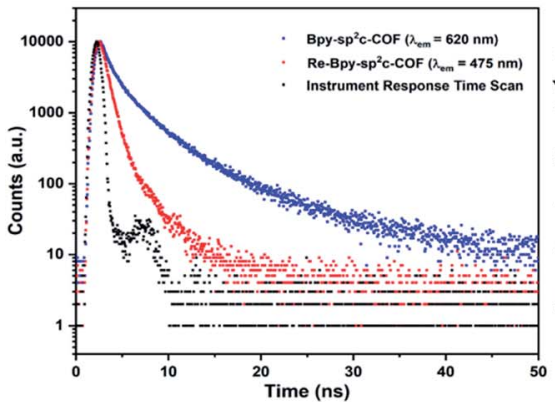

(b)

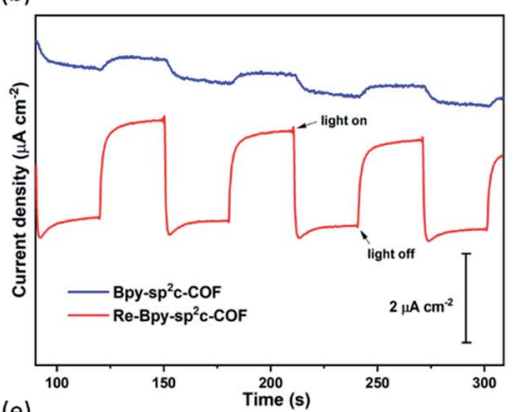

(e)

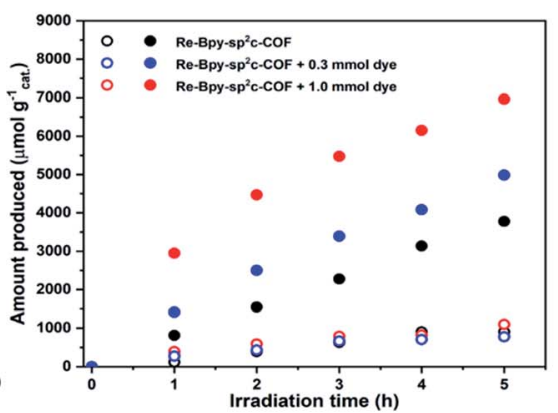

(c)
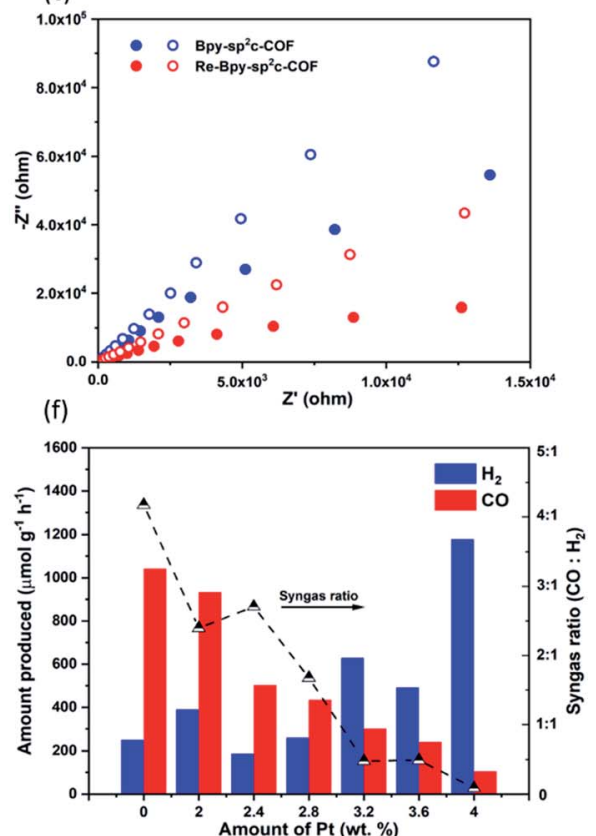

Fig. 3 (a) FT-IR Spectra of ${ }^{13} \mathrm{CO}$ produced in the photoreduction of ${ }^{13} \mathrm{CO}_{2}$ (b) transient photocurrent response at $0.5 \mathrm{~V}$ vs. RHE under intermittent

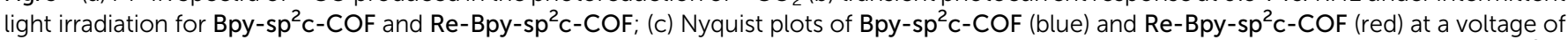
$0.5 \mathrm{~V}$ vs. RHE under dark (open dots) and light irradiation (closed dots); (d) time-correlated single-photon counting experiments for Bpy-sp ${ }^{2} \mathrm{c}-$ COF and Re-Bpy-sp ${ }^{2} \mathrm{c}-\mathrm{COF}$ in MeCN/TEOA (30/1) solution purged with $\mathrm{CO}_{2}\left(\lambda_{\text {exc }}=405 \mathrm{~nm}\right.$ ); (e) CO (closed dots) and $\mathrm{H}_{2}$ (open dots) production using visible light $\left(\lambda>420 \mathrm{~nm}, 300 \mathrm{~W}\right.$ Xe light source) for Re-Bpy-sp ${ }^{2} \mathrm{c}-\mathrm{COF}$ and Re-Bpy-sp ${ }^{2} \mathrm{c}$-COF with dye (1 mg catalyst or $1 \mathrm{mg}$ catalyst with $0.3 \mathrm{mmol}$ or $1.0 \mathrm{mmol}$ dye in $5 \mathrm{~mL}$ solvent with ratio of MeCN/TEOA = 30/1); (f) photocatalytic syngas generation of Pt modified Re-Bpy-sp ${ }^{2} \mathrm{c}-$ COF under visible light irradiation ( $\lambda>420 \mathrm{~nm}, 300 \mathrm{~W}$ Xe light source). 
counting (TCSPC) measurements show the lifetime of the $640 \mathrm{~nm}$ emissive state of Bpy-sp ${ }^{2} \mathbf{c}-\mathbf{C O F}$ is insensitive to the TEOA scavenger (Table S1 and Fig. S21†) and the emission yield is also unchanged (Fig. S20 and S21 $\dagger$ ). In contrast the $475 \mathrm{~nm}$ emission lifetime ( $2.48 \mathrm{~ns}$ to $0.72 \mathrm{~ns}$ ) and yield is very sensitive to the presence of the TEOA electron donor (Fig. S20 and S21 $\dagger$ ), indicating that reductive quenching of this excited state can occur. Previous studies on closely related $\mathrm{sp}^{2} \mathrm{c}$ pyrene COFs have also reported the presence of two emissive states for COF samples. ${ }^{37}$ Therein, emission at $640 \mathrm{~nm}$ was attributed to the presence of a delocalised excited state across both pyrene and the $\mathrm{sp}^{2}$-carbon backbone on the basis of the significantly redshifting of the emission when compared to that typically measured for excimer state of pyrene systems alone ( $c a .480$ $\mathrm{nm}$ ). Interestingly following exfoliation of the COF, a second emission at $c a$. $468 \mathrm{~nm}$ was observed, proposed to be due to exfoliated COF where the removal of the $\pi-\pi$ stacking force allows twisting of the structure and a loss of conjugation across the backbone. Here, the samples are sonicated prior to use and a similar assignment is also proposed.

Addition of the Re catalytic site to the COF framework leads to a marked change in the measured photophysical behaviour. With Re-Bpy-sp ${ }^{2}$ c-COF a single emissive state $\left(\lambda_{\max }=475 \mathrm{~nm}\right)$, proposed to be due exfoliated COF material remains. Such an assignment is in-line with the noted insensitivity of emission at this wavelength to the presence of the Re centre as the loss of conjugation of the exfoliated structure may be expected to prevent efficient electron or energy transfer from the COF framework to the Re centre. Significantly the delocalised COF excited $640 \mathrm{~nm}$ emissive state of Bpy-sp ${ }^{2} \mathbf{c}$-COF is completely absent in the Re-Bpy-sp ${ }^{2} \mathbf{c}$-COF (Fig. S22 $\dagger$ ). The quenching of the emission by the Re centre indicates possible electron transfer from the COF backbone to the catalytically active Re complex. The assignment of the sensitisation of the catalytic centre following photon absorption by the COF framework is supported by the DFT calculations below and the good agreement between the wavelength dependent $\mathrm{CO}$ measurement (Fig. S35 $\dagger$ ) and the excitation spectrum of the $640 \mathrm{~nm}$ emission of the Bpy-sp ${ }^{2} \mathbf{c}$-COF sample (Fig. S20†).

To further explore the photophysics of the system we have also carried out transient absorption (TA) spectroscopic studies on both Re-Bpy-sp ${ }^{2}$ c-COF and Bpy-sp ${ }^{2}$ c-COF (Fig. 4). Following excitation at $400 \mathrm{~nm}, 800 \mu \mathrm{W}(5 \mathrm{kHz})$ of Bpy-sp $^{2} \mathbf{c}-\mathbf{C O F}$ we observe complex TA spectra with broad negative bands between 450 to $c a$. $700 \mathrm{~nm}$ that formed within $0.5 \mathrm{ps}$. There is minimal absorption by the ground state of Bpy-sp ${ }^{2} \mathbf{c}$-COF (Fig. 2d) at wavelengths longer than $600 \mathrm{~nm}$. Therefore, the negative signal is proposed to be the overlap of stimulated emission from both the conjugated Bpy-sp ${ }^{2}$-COF structure $\left(\lambda_{\max }=640 \mathrm{~nm}\right)$ and the exfoliated Bpy-sp ${ }^{2} \mathbf{c}$-COF $\left(\lambda_{\max }=475 \mathrm{~nm}\right)$, overlapped with the ground state bleach, giving rise to the complex shape. The complex nature of the bleach makes determining accurate kinetics challenging, therefore we use $t_{50 \%}$ (the time taken for the bleach to decrease by $50 \%$ ) as a rough measure of the lifetime of the photogenerated excited state. For Bpy-sp $\mathbf{p}^{2} \mathbf{c}-\mathbf{C O F}$ at $550 \mathrm{~nm}, t_{50 \%}=c a .5$ ps (Fig. S46†). Within 0.5 ps a photoinduced absorption (PIA) is present at $770 \mathrm{~nm}$, which decays

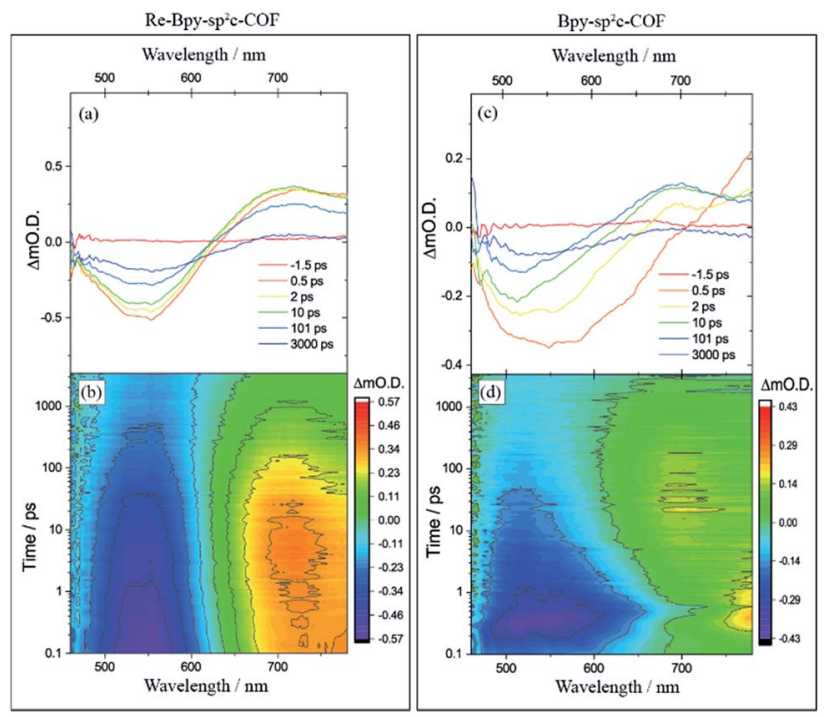

Fig. 4 Transient absorption spectra of (a) Re-Bpy-sp ${ }^{2}$ c-COF and (c) Bpy-sp ${ }^{2} \mathrm{c}-\mathrm{COF}$ at pump-probe time delays chosen to highlight the changing nature of the excited electronic states probed, and the complete transient absorption surface probed (b) Re-Bpy-sp ${ }^{2} \mathrm{c}-\mathrm{COF}$ and (d) Bpy-sp ${ }^{2} \mathrm{c}-\mathrm{COF}$. All spectra are recorded in $\mathrm{CH}_{3} \mathrm{CN}$ following $400 \mathrm{~nm}$ excitation.

within $10 \mathrm{ps}$ to form a new PIA centred at $700 \mathrm{~nm}$ that decays over the course of the experiment to leave only a small PIA by 3 ns.

Re-Bpy-sp ${ }^{2}$ c-COF shows a simpler TA spectrum following $400 \mathrm{~nm}$ excitation (Fig. 4). A negative band is formed, centred at $540 \mathrm{~nm}$, again assigned to a combination of ground state bleaching and stimulated emission from the exfoliated COF framework $\left(\lambda_{\max }=475 \mathrm{~nm}\right.$; Fig. S23 $)$. It is notable that this negative feature is substantially narrower than that observed for Bpy-sp $^{2}$ c-COF and for Re-Bpy-sp ${ }^{2}$ c-COF at $550 \mathrm{~nm}, t_{50 \%}=c a .200$ ps, significantly longer than observed in the absence of the Re. A PIA centred at $c a .770 \mathrm{~nm}$ is again observed to be formed within $0.5 \mathrm{ps}$, with a blue shift of this initially formed PIA observed within the first $5 \mathrm{ps}$, forming a band centred at $\sim 720 \mathrm{~nm}$. This state continues to decay over the course of the time-delays probed, as the negative band assigned to ground state bleaching and stimulated emission, recovers. Although no direct spectral fingerprint is observed for the formation of the reduced Re centre by TA spectroscopy in the UV/vis spectral region, it is clear from the simplification of the TA spectra, combined with the greatly increased lifetime of the ground state bleach, that the presence of the Re centre within the COF leads to the formation of a long-lived charge separated (non-emissive) state.

Density functional theory (DFT) and time-dependent (TD) DFT calculations-performed on representative molecular models Bpy-sp ${ }^{2} \mathrm{c}(\mathrm{L})$ and Re-Bpy-sp ${ }^{2} \mathrm{c}(\mathrm{L})$ of Bpy-sp ${ }^{2} \mathbf{c}-\mathrm{COF}$ and ReBpy-sp's-COF, respectively-show that the electron affinity (EA) and the ionization potential (IP) of both COFs straddle the reduction potential of $\mathrm{CO}_{2}$ to $\mathrm{CO}$, as well as the proton reduction potential, and the oxidation potential of TEOA (Fig. S47 and $\mathrm{S} 48 \dagger$ ). This provides a thermodynamic explanation for the ability of Re-Bpy-sp ${ }^{2}$ - $-\mathbf{C O F}$ to drive $\mathrm{CO}_{2}$ reduction to $\mathrm{CO}$, in the 
presence of the sacrificial agent TEOA. Relative energy levels of the dye and the molecular COF models confirm that it is thermodynamically allowed for excited electrons on the dye to be transferred to Re-Bpy-sp ${ }^{2}$ c-COF (Fig. S48†), in line with the dyesensitization effects observed experimentally.

TD-CAM-B3LYP calculations predict that the lowest-energy, excited electronic state (S1) for both Bpy-sp ${ }^{2} \mathrm{c}(\mathrm{L})$ and Re-Bpy$\mathrm{sp}^{2} \mathrm{c}(\mathrm{L})$ corresponds to the LUMO $\leftarrow$ HOMO transition, with a strong oscillator strength (Table $\mathrm{S} 4 \dagger$ ). Electron distributions of the excited-state frontier orbitals show that for both Bpy$\mathrm{sp}^{2} \mathrm{c}(\mathrm{L})$ and Re-Bpy-sp ${ }^{2} \mathrm{c}(\mathrm{L})$ the HOMO orbital is predominantly located on the pyrene unit of the COF, with the LUMO orbital mainly located on the bipyridine unit (with or without ligated Re complex; Fig. S49 and S50†). Analyses of excited-state, interfragment charge transfer between the building units of the COFs indicate that appreciable amounts of electrons are transferred from the pyrene fragment to the bipyridine fragment (Table S5†), with a sizable electron-hole distance as measured by the charge centroids of the orbitals involved $(\Delta r$ in Table S4 $\dagger$ ). Our computational results clearly support that there is electron transfer from the COF backbone to the catalytically active Re complex upon electronic excitation.

The $\mathrm{CO}_{2}$ reduction mechanism of the COF compared to the homogenous catalysts is therefore different. Here we propose pyrene excitation to a bipyridine based LUMO. In contrast, in solution excitation upon irradiation forms a metal to bipyridine excited state $\left({ }^{3} \mathrm{MLCT}\right)$ which is then quenched by an electron donor. $^{43}$

Crystallinity $^{25}$ and accessible surface area ${ }^{44}$ have been shown to be important factors for the photocatalytic activity of organic photocatalysts. To probe whether these factors also influence the performance of the $\mathrm{COF}$ in photocatalytic $\mathrm{CO}_{2}$ reduction, we synthesized an amorphous analogue by using 1,4-dioxane instead of a 1,2-dichlorobenzene/1-butanol mixture under otherwise exactly the same experimental conditions, Re-Bpy$\mathrm{sp}^{2} \mathrm{c}-\mathrm{P}$ (PXRD, see Fig. S12 $\dagger$ ), which shows low $\mathrm{CO}_{2}$ uptakes and BET surface area (Fig. S19 and S39 $\dagger$ ). Despite having comparable FT-IR, UV-visible and PL spectra (Fig. S8, S15 and S24†), the amorphous polymer showed significantly lower activity for $\mathrm{CO}_{2}$ reduction (Table $\mathrm{S} 2 \dagger$ ) after being loaded with Re with a TON of 2.3 after 12 hours compared to 12.9 for Re-Bpy-sp ${ }^{2} \mathbf{c}$ COF. This highlights that morphological properties, such as crystallinity and porosity, are important in these materials.

We showed previously that COFs that have accessible pores can potentially act as a host for dyes giving rise to increased photocatalytic activity for hydrogen production. ${ }^{25}$ Here, we used $\left(\operatorname{Ir}\left[\mathrm{dF}\left(\mathrm{CF}_{3}\right) \mathrm{ppy}\right]_{2}(\mathrm{dtbpy})\right) \mathrm{PF}_{6}$ (ppy $=2$-phenylpyridine, tbpy $=$

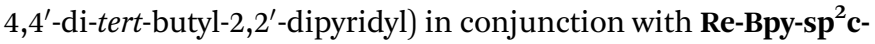
COF to further enhance the photocatalytic performances. Different amounts of the dye were used, and the CO production rates were enhanced by $32 \%$ and $84 \%$ compared to the unsensitized COF when using $0.3 \mathrm{mmol}$ and $1.0 \mathrm{mmol}$ of the dye, respectively, with $1 \mathrm{mg}$ COF over 5 hours (Fig. 3e). The $\mathrm{H}_{2}$ production rates were unaffected. The highest $\mathrm{CO}$ production rates were $1400 \mu \mathrm{mol} \mathrm{h}{ }^{-1} \mathrm{~g}^{-1}$, with a selectivity of $86 \%$ for $\mathrm{CO}$, over 5 hours from Re-Bpy-sp ${ }^{2} \mathbf{c}$-COF loaded with $1.0 \mathrm{mmol}$ dye. It appears to be an electron transfer mechanism between the dye and the COF via oxidative quenching as suggested by emission quenching experiments (Fig. S32 $\dagger$ ).

Finally, we explored Re-Bpy-sp $\mathbf{p}^{\mathbf{c}} \mathbf{c}-\mathbf{C O F}$ loaded with additional in situ photodeposited colloidal Pt as a photocatalyst for syngas production, hence, simultaneous evolution of $\mathrm{CO}$ and $\mathrm{H}_{2}$. Syngas is used in chemical industry on large scale for processes, such as Fischer-Tropsch, and control of the ratio is important. The production of syngas with tunable ratio of $\mathrm{CO}$ and $\mathrm{H}_{2}$ has been reported for electrocatalysts ${ }^{\mathbf{4 5 , 4 6}}$ and inorganic photocatalysts. $^{47,48}$ By adding different amounts of Pt, Re-Bpy-sp ${ }^{2} \mathbf{c}-$ COF could produce high rates of $\mathrm{CO}$-rich or $\mathrm{H}_{2}$-rich mixtures ranging from approximately $4: 1$ to $1: 10$ for $\mathrm{CO}: \mathrm{H}_{2}$ (Fig. 3f).

\section{Conclusions}

In conclusion, we have synthesized a new porous, crystalline bipyridine-containing $\mathrm{sp}^{2} \mathrm{c}-\mathrm{COF}$, which was post-synthetically modified with a rhenium complex to enhance the photocatalytic $\mathrm{CO}_{2}$ reduction performance. Re-Bpy-sp' ${ }^{2} \mathbf{c}-\mathbf{C O F}$ achieved a CO production rate of $1040 \mu \mathrm{mol} \mathrm{g}{ }^{-1} \mathrm{~h}^{-1}$ with $81 \%$ selectivity over $\mathrm{H}_{2}$ over $17.5 \mathrm{~h}$ illumination. This performance was enhanced over 5 hours by up to $84 \%$ by dye-sensitization, giving a CO production rate of $1400 \mu \mathrm{mol} \mathrm{h} \mathrm{h}^{-1} \mathrm{~g}^{-1}$ and a $\mathrm{CO} / \mathrm{H}_{2}$ selectivity of $86 \%$. Based on a range of experimental and computational techniques it appears that Re-Bpy-sp ${ }^{2} \mathbf{c}-\mathbf{C O F}$ operates by a markedly different mechanism compared to the homogeneous catalyst $\left[\mathrm{Re}(\mathrm{bpy})(\mathrm{CO})_{3} \mathrm{Cl}\right]$ which the Re-Bpy-sp ${ }^{2} \mathbf{c}-\mathbf{C O F}$ also outperforms in terms of stability. Crystallinity and porosity seem to be important in these materials since an amorphous, lowporosity analogue showed almost no photocatalytic activity.

\section{Author contributions}

A. I. C. and Z. F. conceived the project. Z. F. synthesized and characterized the materials and performed photocatalysis experiments. L. C. conceived the modelling strategy and L. C. and X. W. performed the calculations. S. Y. C. carried out PXRD analyses. R. S. S. performed the TCSPC experiments. G. N. and A. J. C. carried out isotopic labelling experiments. L. L. performed photoelectrochemical measurements. A. M. G. carried out TA measurements and analysed the results with A. J. C. R. C. and $\mathrm{X}$. L. configured the photocatalysis platform, including setup and methods for GC. R. C., X-Y. W. and L. C. interpreted the gas sorption isotherms. M. B. and X-Y. W. performed STEM imaging. A. I. C., R. S. S. and L. C. co-supervised the project. A. V. provided expertise and feedback. Data was interpreted by all authors and the manuscript was prepared by A. I. C., R. S. S., L. C., and Z. F.

\section{Conflicts of interest}

There are no conflicts to declare.

\section{Acknowledgements}

The authors acknowledge funding from the Engineering and Physical Sciences Research Council (EPSRC) (EP/N004884/1, EP/ 
P034497/1, EP/S017623/1), Newton Fund (EP/R003580/1), and the Leverhulme Trust via the Leverhulme Research Centre for Functional Materials Design. Z. F., X. W. and L. L. thank the China Scholarship Council for a PhD studentship. We thank Dr Jesum A. Fernandes for help with XPS measurements and Dr John Ward for useful discussions.

\section{Notes and references}

1 K. Li, B. Peng and T. Peng, ACS Catal., 2016, 6, 7485-7527. 2 J. Wu, Y. Huang, W. Ye and Y. Li, Adv. Sci., 2017, 4, 1700194. 3 T. Inoue, A. Fujishima, S. Konishi and K. Honda, Nature, 1979, 277, 637-638.

4 J. L. White, M. F. Baruch, J. E. Pander, Y. Hu, I. C. Fortmeyer, J. E. Park, T. Zhang, K. Liao, J. Gu, Y. Yan, T. W. Shaw, E. Abelev and A. B. Bocarsly, Chem. Rev., 2015, 115, 1288812935.

5 Y. Kohno, T. Tanaka, T. Funabiki and S. Yoshida, Chem. Commun., 1997, 9, 841-842.

6 Y. X. Pan, Y. You, S. Xin, Y. Li, G. Fu, Z. Cui, Y. L. Men, F. F. Cao, S. H. Yu and J. B. Goodenough, J. Am. Chem. Soc., 2017, 139, 4123-4129.

7 M. F. Kuehnel, K. L. Orchard, K. E. Dalle and E. Reisner, J. Am. Chem. Soc., 2017, 139, 7217-7223.

8 S. C. Yan, S. X. Ouyang, J. Gao, M. Yang, J. Y. Feng, X. X. Fan, L. J. Wan, Z. S. Li, J. H. Ye, Y. Zhou and Z. G. Zou, Angew. Chem., Int. Ed., 2010, 49, 6400-6404.

9 R. S. Sprick, J. X. Jiang, B. Bonillo, S. Ren, T. Ratvijitvech, P. Guiglion, M. A. Zwijnenburg, D. J. Adams and A. I. Cooper, J. Am. Chem. Soc., 2015, 137, 3265-3270.

10 M. Sachs, R. S. Sprick, D. Pearce, S. A. J. Hillman, A. Monti, A. A. Y. Guilbert, N. J. Brownbill, S. Dimitrov, X. Shi, F. Blanc, M. A. Zwijnenburg, J. Nelson, J. R. Durrant and A. I. Cooper, Nat. Commun., 2018, 9, 4968.

11 R. S. Sprick, L. Wilbraham, Y. Bai, P. Guiglion, A. Monti, R. Clowes, A. I. Cooper and M. A. Zwijnenburg, Chem. Mater., 2018, 30, 5733-5742.

12 X. Wang, K. Maeda, A. Thomas, K. Takanabe, G. Xin, J. M. Carlsson, K. Domen and M. Antonietti, Nat. Mater., 2009, 8, 76-80.

13 J. Lin, Z. Pan and X. Wang, ACS Sustainable Chem. Eng., 2014, 2, 353-358.

14 J. Qin, S. Wang, H. Ren, Y. Hou and X. Wang, Appl. Catal., B, 2015, 179, 1-8.

15 S. Guo, H. Zhang, Y. Chen, Z. Liu, B. Yu, Y. Zhao, Z. Yang, B. Han and Z. Liu, ACS Catal., 2018, 8, 4576-4581.

16 H. P. Liang, A. Acharjya, D. A. Anito, S. Vogl, T. X. Wang, A. Thomas and B. H. Han, ACS Catal., 2019, 10, 3959-3968.

17 C. Yang, W. Huang, L. C. da Silva, K. A. I. Zhang and X. Wang, Chem.-Eur. J., 2018, 24, 17454-17458.

18 S. Wang, M. Xu, T. Peng, C. Zhang, T. Li, I. Hussain, J. Wang and B. Tan, Nat. Commun., 2019, 10, 676.

19 A. P. Côté, A. I. Benin, N. W. Ockwig, M. O'Keeffe, A. J. Matzger and O. M. Yaghi, Science, 2005, 310, 1166-1170.

20 N. Huang, P. Wang and D. Jiang, Nat. Rev. Mater., 2016, 1, 16068.
21 S. J. Lyle, P. J. Waller and O. M. Yaghi, Trends Chem., 2019, 1, 172-184.

22 C. S. Diercks and O. M. Yaghi, Science, 2017, 355, eaal1585.

23 M. S. Lohse and T. Bein, Adv. Funct. Mater., 2018, 28, 1705553.

24 V. S. Vyas, F. Haase, L. Stegbauer, G. Savasci, F. Podjaski, C. Ochsenfeld and B. V. Lotsch, Nat. Commun., 2015, 6, 8508.

25 X. Wang, L. Chen, S. Y. Chong, M. A. Little, Y. Wu, W. H. Zhu, R. Clowes, Y. Yan, M. A. Zwijnenburg, R. S. Sprick and A. I. Cooper, Nat. Chem., 2018, 10, 1180-1189.

26 S. Lin, C. S. Diercks, Y. B. Zhang, N. Kornienko, E. M. Nichols, Y. Zhao, A. R. Paris, D. Kim, P. Yang, O. M. Yaghi and C. J. Chang, Science, 2015, 349, 1208-1213.

27 H. Liu, J. Chu, Z. Yin, X. Cai, L. Zhuang and H. Deng, Chem, 2018, 4, 1696-1709.

28 Y. Fu, X. Zhu, L. Huang, X. Zhang, F. Zhang and W. Zhu, Appl. Catal., B, 2018, 239, 46-51.

29 S. Yang, W. Hu, X. Zhang, P. He, B. Pattengale, C. Liu, M. Cendejas, I. Hermans, X. Zhang, J. Zhang and J. Huang, J. Am. Chem. Soc., 2018, 140, 14614-14618.

30 W. Zhong, R. Sa, L. Li, Y. He, L. Li, J. Bi, Z. Zhuang, Y. Yu and Z. Zou, J. Am. Chem. Soc., 2019, 141, 7615-7621.

31 E. Jin, M. Asada, Q. Xu, S. Dalapati, M. A. Addicoat, M. A. Brady, H. Xu, T. Nakamura, T. Heine, Q. Chen and D. Jiang, Science, 2017, 357, 673-676.

32 R. Chen, J. L. Shi, Y. Ma, G. Lin, X. Lang and C. Wang, Angew. Chem., Int. Ed., 2019, 58, 6430-6434.

33 X. Zhuang, W. Zhao, F. Zhang, Y. Cao, F. Liu, S. Bi and X. Feng, Polym. Chem., 2016, 7, 4176-4181.

34 E. Jin, Z. Lan, Q. Jiang, K. Geng, G. Li, X. Wang and D. Jiang, Chem, 2019, 5, 1632-1647.

35 A. Yassin, M. Trunk, F. Czerny, P. Fayon, A. Trewin, J. Schmidt and A. Thomas, Adv. Funct. Mater., 2017, 17, 1700233.

36 K. M. Choi, D. Kim, B. Rungtaweevoranit, C. A. Trickett, J. T. D. Barmanbek, A. S. Alshammari, P. Yang and O. M. Yaghi, J. Am. Chem. Soc., 2017, 139, 356-362.

37 E. Jin, J. Li, K. Geng, Q. Jiang, H. Xu, Q. Xu and D. Jiang, Nat. Commun., 2018, 9, 4143.

38 J. Hawecker, J.-M. Lehn and R. Ziessel, Chem. Commun., 1983, 536-538.

39 G. Sahara and O. Ishitani, Inorg. Chem., 2015, 54, 5096-5104. 40 T. Nakajima, Y. Tamaki, K. Ueno, E. Kato, T. Nishikawa, K. Ohkubo, Y. Yamazaki, T. Morimoto and O. Ishitani, J. Am. Chem. Soc., 2016, 138, 13818-13821.

41 M. Schwarze, D. Stellmach, M. Schröder, K. Kailasam, R. Reske, A. Thomas and R. Schomäcker, Phys. Chem. Chem. Phys., 2013, 15, 3466-3472.

42 E. E. Benson and C. P. Kubiak, Chem. Commun., 2012, 48, 7374-7376.

43 T. W. Schneider, M. Z. Ertem, J. T. Muckerman and A. M. Angeles-Boza, ACS Catal., 2016, 6, 5473-5481.

44 R. S. Sprick, Y. Bai, A. A. Y. Guilbert, M. Zbiri, C. M. Aitchison, L. Wilbraham, Y. Yan, D. J. Woods, M. A. Zwijnenburg and A. I. Cooper, Chem. Mater., 2019, 31, 305-313. 
45 M. B. Ross, Y. Li, P. De Luna, D. Kim, E. H. Sargent and P. Yang, Joule, 2019, 3, 257-264.

46 M. B. Ross, C. T. Dinh, Y. Li, D. Kim, P. De Luna, E. H. Sargent and P. Yang, J. Am. Chem. Soc., 2017, 139, 9359-9363.
47 J. S. Lee, D. Il Won, W. J. Jung, H. J. Son, C. Pac and S. O. Kang, Angew. Chem., Int. Ed., 2017, 56, 976-980.

48 J.-C. Hu, M.-X. Gui, W. Xia, J. Wu, Y.-N. Zhou, N. Feng, J. Xiao, H. Liu, C.-H. Tung, L.-Z. Wu and F. Wang, J. Mater. Chem. A, 2019, 7, 10475-10482. 